\title{
Las mujeres en la elite política de Baja California Sur 1974-1994
}

Blanca Olivia Peña Molina INSTITUTO MORA

\begin{abstract}
Análisis y evaluación sobre la participación de las mujeres en la elite política-definida como los espacios de los poderes ejecutivo y judicial-siguiendo los criterios de acceso, permanencia y movilidad, para contribuir a la discusión sobre género y poder desde la perspectiva del campo de la construcción de sentido para desentrañar el contenido simbólico en los estereotipos, estrategias e identidades.
\end{abstract}

INTRODUCCIÓN

"Yo me pregunto, sin embargo, si además de sus problemas han llevado su palabra, su manera de entender esta política de la que durante tan largo tiempo han sido excluidas, su crítica a ella. Creo que hasta ahora formulan sus demandas, pero con la palabra tradicional de la política de los hombres, y en la forma en que los hombres la toman."

Rossana Rossanda

$\mathrm{E}$ $\mathrm{n}$ los últimos años ha surgido un inusitado interés por el análisis de las relaciones entre las mujeres y el poder político, interés que se ha visto plasmado en estudios dedicados a caracterizar las formas particulares de participación de las mujeres dentro de los partidos políticos, en los procesos electorales, los movimientos urbanos y/o ciudadanos $y$, aunque en menor grado, en la subrepresentación que, hoy por hoy, aún persiste en los distintos órganos de gobierno, sean éstos federales y/o estatales.

Llama la atención sin embargo que este interés no haya aflorado, en grado similar, en investigaciones sobre la presencia de las mujeres en las elites políticas que trasciendan el tono de 


\section{ex libris}

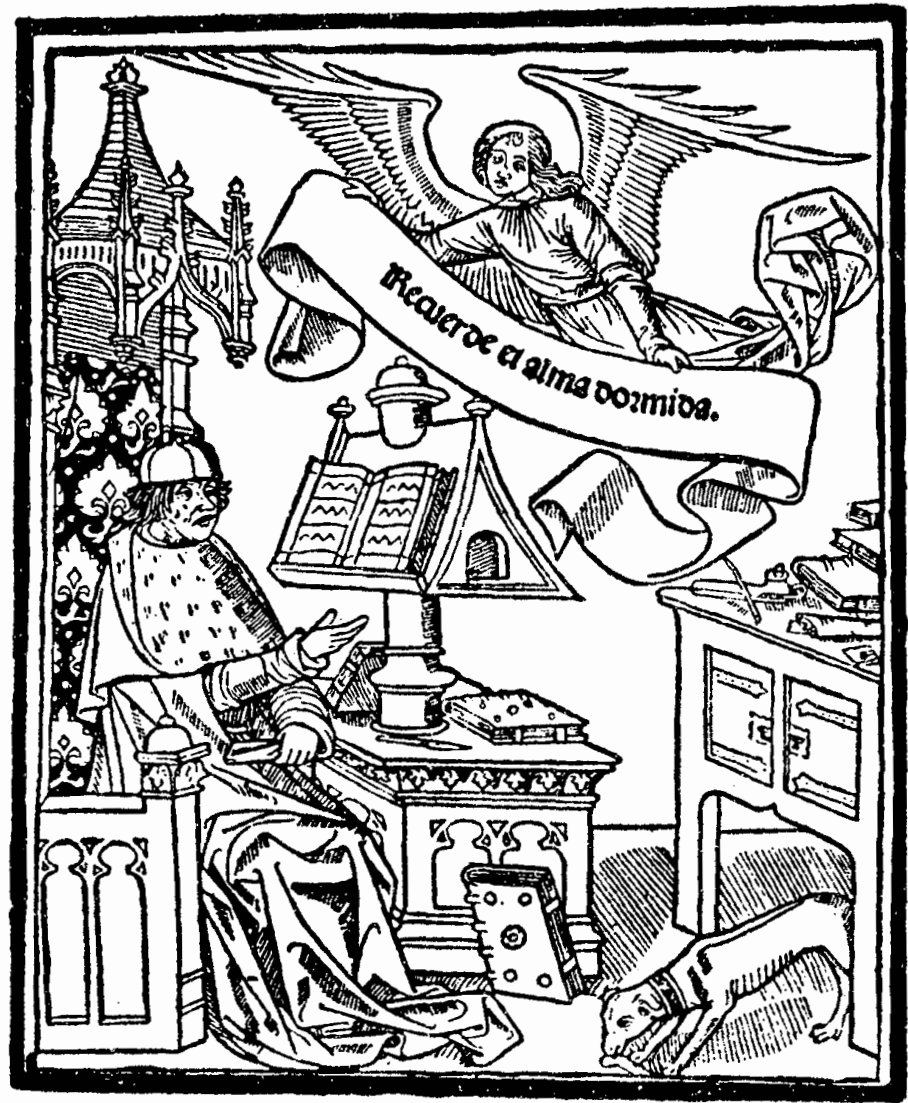

Yaime Peguero 
denuncia de una situación política injusta (la subrepresentación), que aunque cierta, es insuficiente para dar cuenta de las vicisitudes de la incorporación, permanencia y movilidad de las mujeres en las elites, de los obstáculos a vencer, de las estrategias esgrimidas, de los itinerarios utilizados, así como de la identidad de género de las que "ejercen poder" en un espacio considerado tradicionalmente como "masculino". ${ }^{1}$ Baja California Sur no es la excepción en este sentido.

Las mujeres estamos subrepresentadas en el interior de las elites políticas que es donde se concentra el poder político y donde se deciden los asuntos públicos. Los estudios "clásicos" sobre dichas elites no concedían importancia, o muy escasa, a la pre-

\footnotetext{
${ }^{1}$ El género se ha definido como una red de creencias, rasgos de personalidad, actitudes, sentimientos, valores, conductas $y$ actividades que diferencian a mujeres y varones (Burín y Bleichmar, Género, 1996); como una categoría de análisis en que se articulan tres instancias básicas: $a$ ) la asignación de género, $b$ ) la identidad de género, y c) el papel de género (Lamas, "Antropología", 1986); o bien, como un elemento constitutivo de las relaciones sociales basadas en las diferencias que distinguen los sexos donde el género es una forma primaria de relaciones significantes de poder (Scott, Género, 1996).

El resultado de tal diferenciación entre los géneros masculino y femenino se traduce en una posición de desigualdad y jerarquía entre ambos, es decir, en un tipo de relación social donde los cambios en las representaciones del poder ( $y$ sus actores), no tienen una dirección unívoca. Lo anterior significa que el estatus de la mujer en la vida social humana no se explica, exclusivamente, en sentido directo de las cosas que hace, sino del significado que adquieren sus actividades a través de la interacción social concreta.
}

sencia de mujeres en ellas. Para Vicky Randall, ${ }^{2}$ los pocos estudios sobre la presencia femenina en este ámbito se enfrentan al problema de los datos, pues continúan siendo fragmentarios en los estudios sobre su participación $y$, sobre todo, acerca de las que forman parte de la burocracia política propiamente dicha, dado que, en términos de poder político y en opinión de la autora, las legislaturas no son, o son menos importantes, que la burocracia política, como medios de representación.

La afirmación anterior conviene al caso mexicano por dos razones: a) la primera, porque en México es en el poder legislativo donde, históricamente, se ha concentrado el mayor número de mujeres, y $b$ ) porque es en la burocracia política (poder ejecutivo y judicial) donde las pautas de incorporación, permanencia, movilidad y tipo de cargos de las mujeres son más inestables y desequilibradas que las de los varones.

La extraordinaria subrepresentación de las mujeres en las socicdades que se reclaman como democráticas, debe considerarse un serio problema; sin embargo, a la pregunta de si debería haber más mujeres que representaran a las mujeres, no podemos contestar en forma mecánica. Bl tema de la representación no es una materia fácil; depende, entre otras cosas, del sistema de partidos y del sistema electoral de cada país en particular, de las características propias de su burocracia política y, en forma especial,

${ }^{2}$ Randall, Woman, 1987, p. 95. 
de la denominada "identidad de género" de quienes la conforman.

Los resultados que se exponen a continuación, forman parte de un proyecto de investigación más amplio; este artículo se apoya en cifras y utiliza, intencionalmente, la diferenciación sexual para caracterizar la subrepresentación de las mujeres en los órganos de gobierno del estado de Baja California Sur. Intenta también presentar algunas "señas de identidad de género" de las funcionarias (obtenidas en entrevistas de fondo) que en otro lugar son interpretadas con mayor profundidad. ${ }^{3}$

MUJERES Y ELITE POLITICA:

SE ABRE LA BRECHA

La incorporación de mujeres a los órganos de gobierno es, en el caso de Baja California Sur, muy tardía y precaria respecto a la presencia de mujeres en el ámbito federal. Lo anterior se explica, por lo menos parcialmente, debido a la condición de subordinación política en que vivió por largos años este territorio respecto al poder ejecutivo federal. Fue durante el porfiriato, específicamente en 1888 , cuando la península de Baja California se dividió en dos distritos, el norte y el sur, y no sería sino hasta 1931 (durante el gobierno de Pascual Ortiz Rubio) que se le concedería el estatuto político de territorio. Sabemos que el establecimiento del nuevo orden posrevolucionario requirió de formas de control político que garantizaran la con-

${ }^{3}$ Peña, "Identidad", 1997.

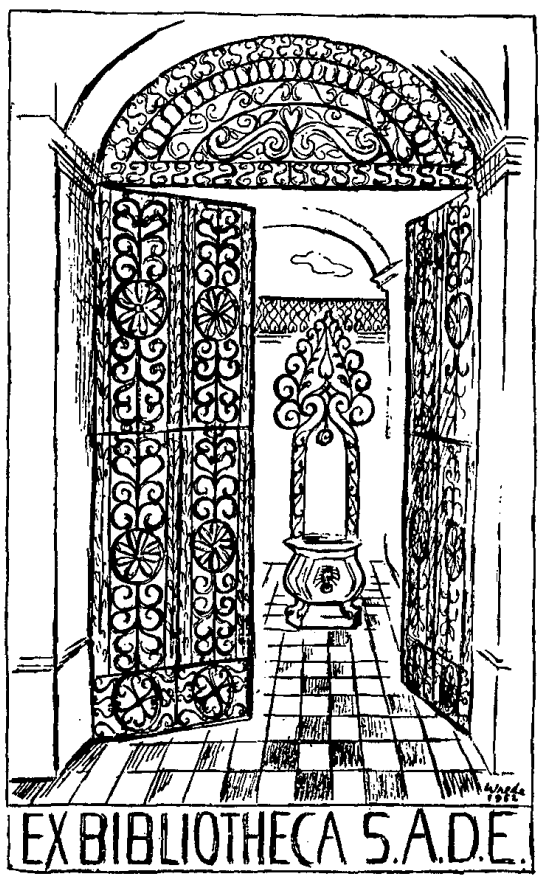

centración del poder, sobre todo en aquellas regiones del país donde múltiples intereses y cacicazgos constituían un obstáculo para lograrlo. A pesar de ello:

El territorio sur de Baja California, era una de las regiones donde no había podido consolidarse un grupo de poder, un líder o un cacique cuya influencia social, económica, política o militar representara una instancia relevante con la cual el poder central tuviera que negociar. El estatuto político de territorio reflejaba bien esa condi- 
ción: se trataba de una región geográfica en dependencia directa del poder central, jefaturada por un gobernador designado discrecionalmente por el presiclente en turno. ${ }^{4}$

De ahí que, de 1931 a 1965, la vida política en el territorio se caracterizara por la presencia de gobernantes de extracción militar, así como por una clase política en recomposición a nivel local, que pugnaba por acceder a los cargos públicos. Este grupo materializó sus demandas en un discurso de corte regionalista que exigía reivindicaciones políticas muy concretas; protagonista de éstas fue el denominado Frente de Unificación Sudcaliforniano (FUS), movimiento civilista que, al reclamo de gobernantes civiles sumó posteriormente la demanda de que éstos fueran nativos o con arraigo, paralela ésta al anhelo de restitución de la vida municipal en el territorio que había sido anulada en 1928 .

Se afirma que, desde 1929 hasta principios de los años sesenta, las actividades partidistas fueron intermitentes y centradas en la elección del diputado federal que cada tres años constituía el único acontecimiento político en la región. Existió allá una estructura del Partido Nacional Revolucionario y algunas células del Partido Comunista Mexicano, sin embargo, durante este periodo ni el partido oficial ni la oposición tuvieron otra actividad que no fuera electoral ni contaron con una estructura permanente. No fue sino hasta mediados de la década de los sesenta que el PRI tu-

\footnotetext{
"Preciado, "Producción”, 1993, p. 112.
}

vo una estructura organizativa estable en todo el territorio, teniendo como principales partidos políticos opositores al Partido Popular Socialista y al Partido Acción Nacional.

El Frente de Unificación Sudcaliforniano se mantuvo activo durante 21 años (1944-1965), mismos por los que Hugo Cervantes del Río transitó hasta que en 1965 fue nombrado gobernador del territorio, cumpliéndose así con la exigencia de contar con un gobernante civil.

En 1969 se gestó un movimiento de opinión que hizo suya la demanda del Fus "pro gobernador nativo o con arraigo", del cual el consejo editorial del semanario El Eco de California era el principal portavoz. Declarado explícitamente no partidista, este scmanario convocó a una asamblea en la ciudad de Loreto para constituir el Cuerpo Colegiado de Integración Politica de Sudcalifornia (CCIPS); inspirado en la autodeterminación de los pueblos y bajo la consigna "Por la conquista y el reconocimiento de un derecho" nacería el movimiento civilista denominado Loreto 70 . Concluida la gestión gubernamental de Cervantes del Río, en ese mismo año, y siendo presidente de la república Luis Echeverría Álvarez, se designó a Félix Agramont Cota como sucesor con carácter provisional, de Cervantes del Río.

Con esta designación, Echeverría lograría dos propósitos: cumplir con la demanda de tener un gobernante civil y nativo, y transitar hacia la conversión del territorio en un estado. Dicho tránsito hizo más patente la lucha por los cargos públicos, lucha en que se enfrentarían algunos perso- 
najes vinculados con los movimientos civilistas, así como otro grupo de sudcalifornianos que ya había formado parte de la administración de Cervantes del Río y que se mantuvo al margen de los primeros.

Durante la gestión de Agramont Cota como último gobernador del territorio, se dieron dos fenómenos importantes, dignos de mención: la reinstalación de los municipios libres y el nacimiento de Baja California Sur como entidad federativa. Con ello se satisfacían las expectativas de algunos sudcalifornianos de formar parte de la naciente elite política local.

"Naturaleza es destino...". Las mujeres en los órganos de gobierno

La presencia de mujeres en las altas jerarquías de la administración pública y en los puestos de elección popular en México data de los años cincuenta, debido, fundamentalmente, a su tardía consecución del sufragio, de lo que, cuantitativamente hablando, se derivan cifras poco significativas. ${ }^{5}$ En lo que respecta al poder ejecutivo y judicial, durante el gobierno de Cervantes del Río (1965-1970), cuando Baja California Sur tenía aún la categoría política de territorio, de un total de $\mathbf{4 8}$ funcionarios públicos (federales, territoriales y de oficinas descentralizadas), ninguno era mujer. De igual forma, en el periodo que comprende la gestión de Agramont Cota como gobernador provisional del territorio, y a pesar de que este gobernante era nativo, no

"De Silva, "Mujeres", 1989, p. 269. encontramos un panorama muy distinto del anterior, tan sólo $3.1 \%$ del total de funcionarios fueron mujeres (cuadro 1).

Se desconocen las causas por las cuales las mujeres no tuvieron mayor presencia en los órganos de gobierno, habida cuenta de que muchas de ellas participaron activamente en los movimientos civilistas. Un hecho sí es significativo: el cambio en el cstatuto político de territorio a estado aparece como una condición que incrementaría su presencia en la escena pública y así lo atestiguan los siguientes datos. Del total de funcionarios que, en los dos últimos gobiernos territoriales y cuatro gobiernos estatales, han ocupado cargos en los niveles medios y altos del poder ejecutivo y judicial $^{6}$ en esta entidad, $82 \%$ han sido hombres y $18 \%$ mujeres; asimismo identificamos el sexenio de 1987 a 1993 como el periodo donde el porcentaje de mujeres $(30.9 \%)$ ha sido el más elevado de toda la serie histórica (cuadro 1). Si bien la "cuota" de participación de mujeres ha ido en aumento, ésta se explica por el crecimiento en el número absoluto de funcionarios en cada administración, dado que se presentan variaciones porcentuales significativas entre hombres y mujeres de un sexenio a otro. De ahí que "...contrariamente a lo que se piensa, la participación de la mujer en la polí-

\footnotetext{
6 Para el poder ejecutivo se consideraron los siguientes cargos: administración, jefaturas de departamento, direcciones, subdirecciones, secretarías, subsecretarías y gubernatura; en el poder judicial, jueces, subprocuradores, procuradores, oficial mayor, magistrados y presidentes del tribunal superior de justicia.
} 


\section{SECUENCIA}

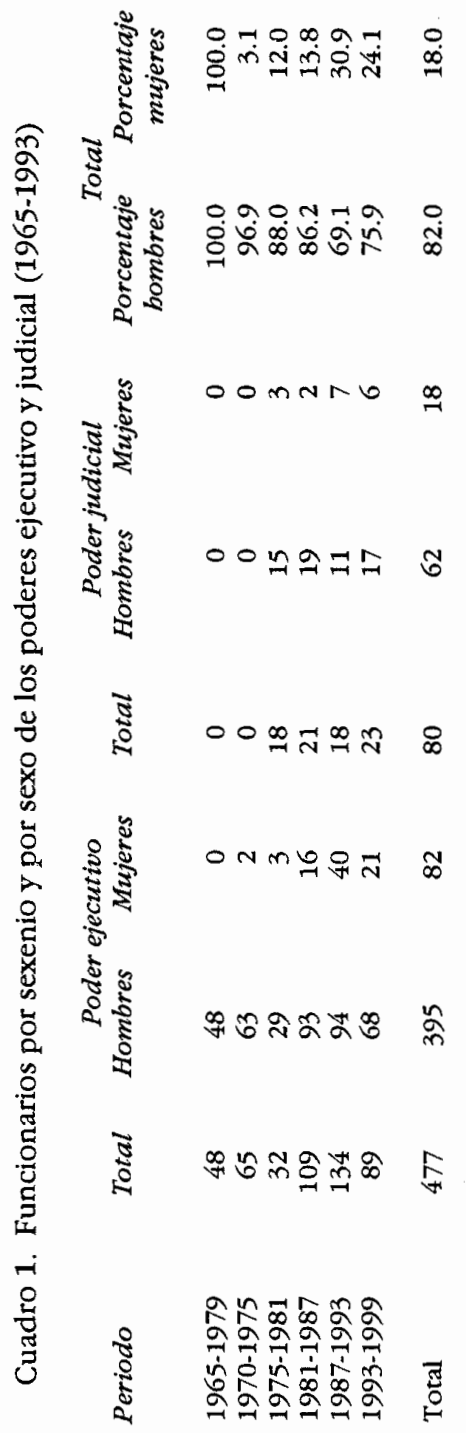




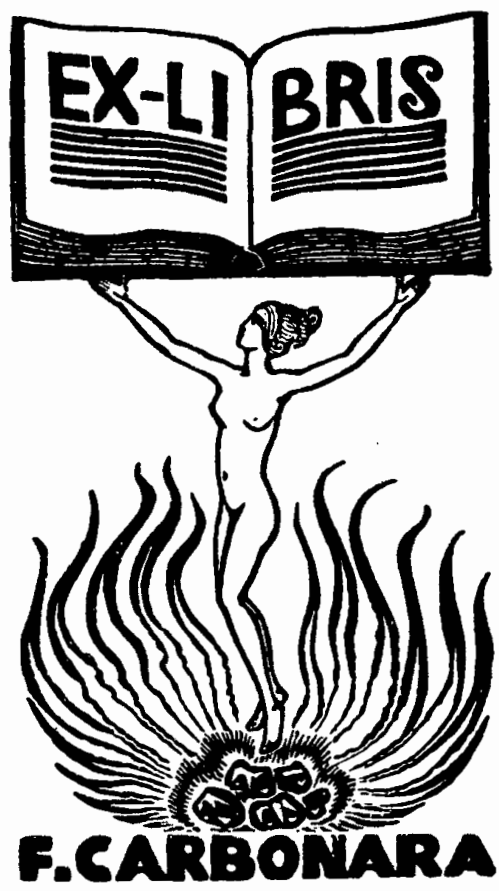

tica no ha sido continua, lineal, concertada y ascendente". ${ }^{7}$

El tipo de cargos ocupados por las mujeres en el poder ejecutivo parecen apoyar la afirmación anterior, pues son las direcciones y las jefaturas de departamento, respectivamente, los puestos donde se ha concentrado el mayor número de funcionarias públicas (cuadro 2). Este fenómeno se apoya en el supuesto de que el modelo

\footnotetext{
${ }^{7}$ Farías, "Participacion", 1988, p. 695.
}

de incorporación de las mujeres al sector público se da en aquellos cargos con mayor densidad de gestión técnica, según la pirámide organizacional vigente de la burocracia política $y$, en este sentido, reproduce la tendencia que se observa a nivel federal:

En el poder ejecutivo federal y, concretamente, en mandos medios hacia arriba, hay un cinco por ciento de mujeres que, en cifras, significa medio centenar para poco más de un millar de puestos. En este mismo poder, y según también la información recopilacla, hay unas 79 mujeres en cargos administrativos, esto es, el siete por ciento de participación femenina, micntras el total de personas en este rango es de más de mil. ${ }^{\circ}$

Cabe hacer notar que, si bien el número total de mujeres en la actual administración se vio reducido a $24.1 \%$ respecto a $30.9 \%$ del sexenio inmediato anterior, es la primera vez que tres mujeres ocupan cargos como subsecretarias siendo éstos la Subsecretaría de Gobierno, la Subsecretaría de Finanzas y la Subsecretaría de 'Turismo (cuadro 2). De nuevo la situación a nivel federal no ofreció un panorama muy diferente:

En México, en los últimos cuarcnta años, ocuparon cargos a nivel del cjecutivo federal como secretarias y subsecretarias de Estado un total de quince mujeres - de las cuales tres obtuvieron el rango de ministras y cloce de subsecretarias- frente a 522 hombres. ${ }^{9}$

\footnotetext{
"Martínez, "De poder", 1993, p. 49.

${ }^{9}$ Farías, "Participación", 1988, p. 695.
} 
Cuadro 2. Tipo de cargos ocupados por mujeres, poder ejecutivo por sexenio (1975-1993)

Cargo

Periodo

$\begin{array}{lccccc} & 1975-81 & 1981-87 & 1987-93 & 1993-99 & \text { Total } \\ \text { Gobernador } & 0 & 0 & 0 & 0 & 0 \\ \text { Secretario } & 0 & 0 & 0 & 0 & 0 \\ \text { Subsecretario } & 0 & 0 & 0 & 3 & 3 \\ \text { Contralor } & 0 & 0 & 0 & 0 & 0 \\ \text { Oficial mayor } & 0 & 0 & 0 & 0 & 0 \\ \text { Director } & 3 & 5 & 20 & 3 & 31 \\ \text { Subdirector } & 0 & 3 & 3 & 9 & 15 \\ \text { Procurador } & 0 & 0 & 3 & 1 & 4 \\ \text { Jefe depto. } & 0 & 6 & 12 & 4 & 22 \\ \text { Administrador } & 0 & 2 & 2 & 1 & 5 \\ \text { Total } & 3 & 16 & 40 & 21 & 80\end{array}$

FuENTE: Directorio de funcionarios por sexenio, Archivo del Gobierno del Estado de BCS. Cuadro elaborado por la autora.

Cuadro 3.' Permanencia de mujeres poder ejecutivo: 1970-1993

Núm. de administraciones

Una administración

Dos administraciones

Tres administraciones

Cuatro administraciones
Mujeres

80

13

4

1
Porcentaje

81.6

13.3

4.1

1.0

FUENTE: Número total de mujeres y su permanencia en una o más administraciones. Directorio de funcionarios públicos, Gobierno del Estado de BCS. Cuadro elaborado por la autora.

Otro dato interesante que nos permite evaluar la participación de las mujeres en la elite política lo constituye su permanencia y movilidad laboral; de un total de 98 mujeres que han ocupado cargos en poder ejecutivo y judicial, $4.1 \%$ manifiestan haber desem. peñado algún puesto en tres administraciones continuas, $13.3 \%$ en dos y $81.6 \%$ en una (cuadro 3 ). Podemos afirmar que, por razones de experiencia, las mujeres identificadas entre las de mayor permanencia son las que han llegado a ocupar cargos de importancia política; pero se observa también que están siendo sustituidas, paulatinamente, por mujeres más jóvenes y con perfiles profesionales distintos (administradoras públicas, contadoras públicas, abogadas, etc.) a los de las 


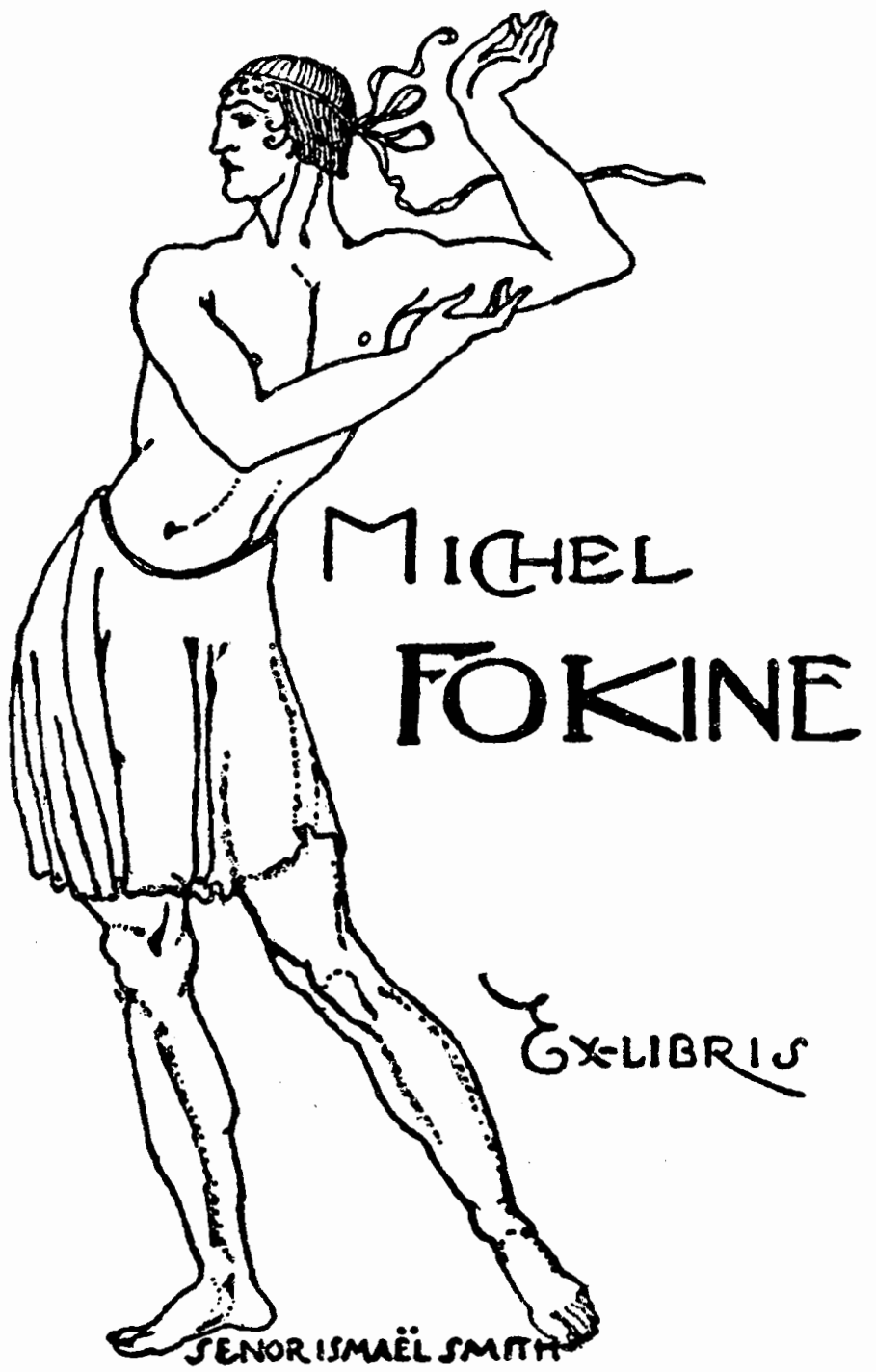


primeras (maestras de primaria y preescolar).

Esta situación refleja que la movilidad laboral de las mujeres funcionarias es mucho más compleja y limitada, sin embargo, podría por lo menos explicarse a partir de las siguientes consideraciones: $a$ ) falta de acceso a oportunidades para su desarrollo (movilidad vertical) o permanencia (movilidad horizontal); $b$ ) falta de acceso a la estructura informal de poder de la dependencia (toma de decisiones), y c) desequilibrio numérico en los puestos más altos de la estructura organizacional (minoría de mujeres respecto al total de hombres).

Se afirma que los sistemas organizativos que restringen las oportunidades y el poder, tanto de hombres como de mujeres, no desarrollan cabalmente los recursos y las potencialidades de ninguno de ellos; pero también es cierto que las mujeres enfrentan situaciones, en algunos casos, de siglos de una tradición que las ha relegado a un papel de subordinación. De ahí que la presencia de mujeres en cargos por designación en los órganos de gobierno no es garantía de que se vaya erradicando la ideología que apoya los valores socioculturales que legitiman el ejercicio de la autoridad masculina. Lo anterior puede explicarse si entendemos que una estructura organizativa constituye un sistema abierto y que el contexto cultural pone un límite a las posibilidades de cambio de actitudes y de comportamiento de las personas; por este motivo, las leyes, normas y usos culturales impactan aún las técnicas y las filosofías adminis. trativas más sofisticadas.
En síntesis, se puede afirmar cue las mujeres se encuentran en desventaja en una organización jerárquica, como lo es el sector público, en relación con tres factores: oportuniclad, poder y número:

En los lugares en que los incentivos y la posición se tornan crecientemente escasos al acercarse a la cima, cloncle es grande en particular la brecha entre "profesionales" o administradores y otros trabajadores, $y$ donde predominan los modelos burocráticos rígidos de organización de tareas, también es probable que exista un grupo de empleados desaprovechados y subutilizacos, y las mujeres, típicamente, se concentran en ese grupo. En dichos sistemas, donde la mayoría de las empleadas están segregadas en puestos de bajo nivel, las pocas mujeres que ocupan puestos superiores $y$, por ende, tienen oportunidad y acceso al pocker, enfrentan la otra desventaja de clesigualdad en número. ${ }^{10}$

Otro indicador útil en el análisis de la movilidad laboral de las mujeres en los órganos de gobierno es el tránsito que algunas de ellas han realizado de uno a otre (movilidad horizontal). Los datos indican que del total de mujeres con mayor permanencia en el sector público, la movilidad horizontal más acentuada se da entre el poder ejecutivo y el poder legislativo, dado que las mujeres que han ocupado cargos en el poder judicial presentan una movilidad menor y tienden a permanecer en el mismo puesto (jueces o magistrados).

${ }^{10}$ Moss, "Cambio", 1990 , p. 17. 


\section{"Mujer que sabe latín...": educación $y$ trabajo}

Aun en los casos donde las funciones del cargo exigen el dominio de conocimientos, habilidades y experiencia, las funcionarias viven sorteando los estereotipos de la "mujer pública" y la "mujer tradicional": ¿Hasta dónde esta doble imagen es vivida como contradictoria por las funcionarias?, ¿qué obstáculos han enfrentado?, ¿qué itinerarios forman parte de su vida cotidiana? De los testimonios orales obtenidos hasta ahora, podemos decir que el papel de mujer tradicional se incorpora al de funcionaria política/pública, lo cual implica sumar a sus "obligaciones" como esposa-madre-ama de casa, todas aquellas actividades que la responsabilidad del cargo les confiere. Cuentan para ello con una infraestructura de apoyo doméstico que las "libera temporalmente": transfiriendo el trabajo hacia otras personas (choferes, trabajadoras domésticas, familiares mujeres, entre otras). Sin embargo, es importante vigilar la "imagen pública": nunca puede abandonar el sentimiento de obligatoriedad exigido socialmente a su papel de mujer. Primero "mujer", luego funcionaria política.

...soy la primera mujer contador mayor de Hacienda en esta Legislatura aquí en el estado $[\ldots]$ a la mujer le ha costado más trabajo ir demostrando que tiene la misma capacidad, la misma sensibilidad para salir adelante $[. .$.$] naturalmente$ uno tiene que cuiclar una imagen y una línea de conducta. Siempre he comentado que tu vida privada, tu vida personal, aunque digas que es muy aparte de mi trabajo, sí incide; incide porque tú tienes que presentar una imagen; si a ti te ven, por ejemplo, que todas las noches sales, naturalmente solsra quien te vea, más en un lugar tan pequeño, entonces esas personas pueden clecir: "sí, es muy capaz en su trabajo, pero su vida privada"... ¿Cómo voy a actuar ahora que me divorcié?...Pues voy a actuar de esta forma: no a comidas, no cenas, dedicarme a mi familia y sacarla... eso requiere mucho tiempo. ${ }^{11}$

Las funcionarias son, en su mayoría, madres, lo cual significa que sus itinerarios difieren del papel de "mujer tradicional", dado que su trabajo excede con mucho las ocho horas diarias. Una regla no escrita para las que tienen acceso a la esfera política parece indicar que en ella se prefiere a aquellas con un perfil profesional para ejercer el cargo y además:

[...] significa que tienes que casarte, tener hijos y vivir un papel de mujercasada-política, decir que vienes de dejar a los niños y, a pesar de todo, estar en la asamblea del partido o en la asamblea de gobierno [...] para ese tiempo yo era francamente un desmadre $y$ no correspondía al modelo serio de mujer [...] no importaban tus facultades, importaba que parecieras una mujer seria, vestirte de un estilo, vivir de un estilo, no verte jamás sola después de las cliez de la noche en la calle, todo eso implica ser una mujer funcionaria, respetable, moral, decente. ${ }^{12}$

${ }^{11}$ Testimonio oral obtenido de lit C.P. Ada Silvia Carrillo Bareño, cCSYH-UABCS, Archivo de la Palabra, Serie Mujeres, La Paz, 1994. También ha ocupado los cargos de administradora de la SAHOPE y la tesorería del Municipio de La Paz.

${ }^{12}$ Testimonio oral obtenido de Cinthia Castro Iglesias, CCSYS-UABCS, Archivo de Ia Palabra, 
En relación con el acceso a oportunidades de desarrollo (movilidad vertical), nuestra investigación ha podido constatar que existe un "sesgo profesional generacional" entre las primeras funcionarias (sobre todo las que vivieron la transición política de Baja California Sur, de territorio a estado) y las denominadas funcionarias políticas "técnicas'" (en su propio término). Este sesgo se manifiesta no sólo en la variable edad, sino fundamentalmente en los niveles de escolaridad: entre las primeras predominan las normalistas (maestras de enseñanza primaria, media y media superior), y entre las segundas, la mayoría ha realizado estudios universitarios. Este dato es importante en virtud de que las mujeres que en la presente administración ocupan los puestos más altos en la pirámide organizacional, responden a los perfiles profesionales requeridos por el cargo y tienen una permanencia promedio en el sector público de seis años. Paralelamente, como ya se indicó en párrafos anteriores, el desequilibrio numérico entre hombres y mujeres en estos puestos no favorece a las funcionarias. Sin embargo, esta afirmación no significa que, si el número de mujeres fuera más elevado, no estarían mejor representadas. Ello continuará apareciendo como un enunciado teórico y/o una intención política.

Serie Mujeres, La Paz, 1993. Ocupó los cargos de directora de Casas de Cultura en el estado y de subdirectora de Cultura en la pasada administración. "La politica es cosa de hombres...":
militancia partidista

En el caso de las mujeres con mayor permanencia en la administración pública, y contrariamente a lo que podría suponerse, no es la militancia en el partido oficial (PRI) una condición previa a su incorporación. En los testimonios orales encontramos que son más bien el nivel de estudios y la experiencia, las condiciones que influyen en esta situación:

Estoy afiliada al partido, alguien me invitó, era algo muy esporádico, con una participación muy insignificante, no me considero militante activa ni mucho menos. Les decía: "es que yo no sirvo para eso, mi trabajo es muy técnico" $[\ldots]$ mi estancia dentro del particlo se ha limitado a estar como espectador, no a participar directamente $[\ldots]$ yo vengo de la iniciativa privacla $y$ he estado muy reacia a aceptar participar en el gobierno, en el sector público, porque me parecía que las cosas no estaban bien, lo mismo me pasa con las cuestiones del partido $[\ldots]$ no me gusta andar con mentiras o con falsas promesas y he cuestionado mucho a los dirigentes porque no se ubican en la realidad $[\ldots]^{13}$

Las relaciones personales y/o de parentesco constituyen una variable importante en lo que respecta a la militancia partidista de las mujeres funcionarias; la mayoría se ha incorporado al Partido Revolucionario Institu-

${ }^{13}$ Testimonio oral obtenido de la C.P. Griselda Uribe Figueroa, cCSYH-UABCs, Archivo de la Palabra, Serie Mujeres, La Paz, 1994. Actualmente ocupa el cargo de subsecretaria de Finanzas. 


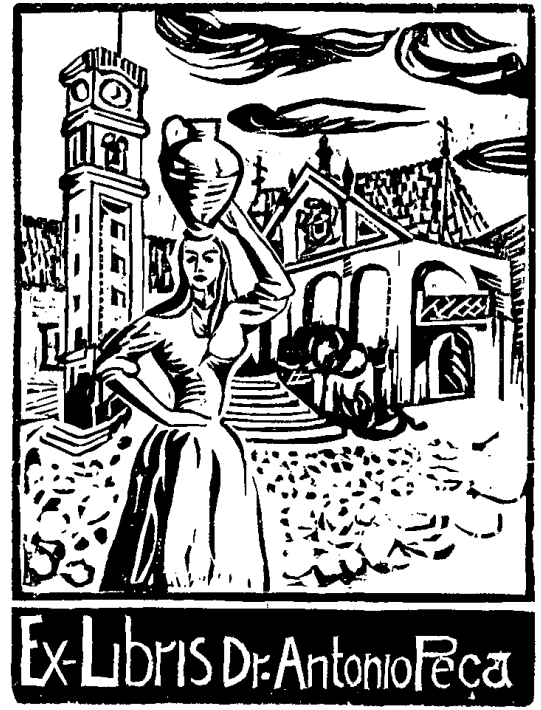

cional después de un tiempo "razonable" de permanencia en el sector público invitadas por algún amigo(a) o pariente. También existen casos donde encontramos la situación contraria y más frecuente en nuestro país: la militancia en el PRI, previa a su incorporación al servicio público, por influencia familiar. Esta dualidad es importante en virtud de que son las funcionarias sin militancia previa en el PRI quienes pueden ser calificadas de funcionarias "políticas con una trayectoria exitosa"; mientras que las pautas de incorporación y permanencia de las funcionarias con militancia previa en este partido nos hablan de un proceso de "entrada-salida-entrada", sujeto al reacomodo sexenal de los grupos políticos que acceden al poder y que es una característica más vinculada a las mujeres que hacen carrera política en las legislaturas estatales y federales.

Lo anterior no significa quc las funcionarias "políticas técnicas" se mantengan al margen de las actividades del PRI (generalmente en sus organizaciones de actividades femeninas), de hecho participan pero colateralmente, dado que no constituye para cllas lo más importante. Un testimonio interesante de una ex funcionaria con militancia previa en dicho particlo es el siguiente:

Por azares del destino, de un destino que nunca sé si realmente ocurre sin la voluntad de otras gentes, me vi inmersa, durante todos estos años (estoy hablando de casi once años), en la política traclicional, partidista, oficial; en el PRI milito, militaba activamente hace tres años todavía. Hay dos maneras de jugar este ajedrez político hombremujer: una es a través del CIM para filtrar la mayor cantidad posible cle mujeres, siempre por una líder que ellos saben que va a responderles y, por otro lado, la participación de la mujer en puestos del poder judicial o legislativo, que casi nunca son emanadas cle estos filtros. El primer grupo de mujercs está en niveles bajos medios, nunca llegan a nivel de mando medio superior en la administración; siempre están abajito de alguien, por eso el CIM piercle fuerza [...] al segundo grupo de mujeres se les considera las "técnicas", las serias, las que no les interesa la política, les interesa la administración públici... ${ }^{14}$

La relación entre las mujerces y los partidos políticos es un tema muy discutido pero poco investigado. Sc igsias.

${ }^{14}$ Testimonio oral de Cinthia Castro Igle- 
noran las causas, intereses y caracterís ticas que motivan la militancia parti. dista de muchas mujeres. Si se acepta que en la vida de los hombres, en tanto género, existe una continuidad entre ésa y la política, no sucede lo mismo en el caso de las mujeres. Se afirma que "fueron excluidas de la polis"; pero no sólo fueron excluidas, sino que se construyeron formas de organización de lo privado, de la reproducción de la sociedad y de la organización de la producción, que hicieron de la exclusión una constante. Irrum. pir en la política formal, vista de cerca por el ojo de algunas mujeres, "llega a ser una palabra que emite un sonido nuevo, ambiguo, distinto según la edad y las formas [...] [en] que han tomado contacto con ella $[. .$.$] es una pa-$ labra problemática". 15

La presencia de las mujeres en la política formal que, en sentido estricto, es "el lugar donde se deciden los asuntos públicos", data en México de fechas relativamente recientes. También sabemos que, por largos años en nuestro país, la única y más segura vía para llegar a ocupar un cargo de elección o de designación lo constituyó la pertenencia al denominado partido oficial o partido del gobierno. Este rasgo es interesante en el tema que nos ocupa dado que, si bien puede explicar por qué algunas mujeres priístas acceden al ejercicio del poder por esta vía, no explica las motivaciones de aquellas mujeres de base que militan en diferentes sectores de este partido.

En el caso de las mujeres, sabemos que, de los tres órganos de gobierno a

\footnotetext{
${ }^{15}$ Rossanda, Otras, 1982 , p. 83.
}

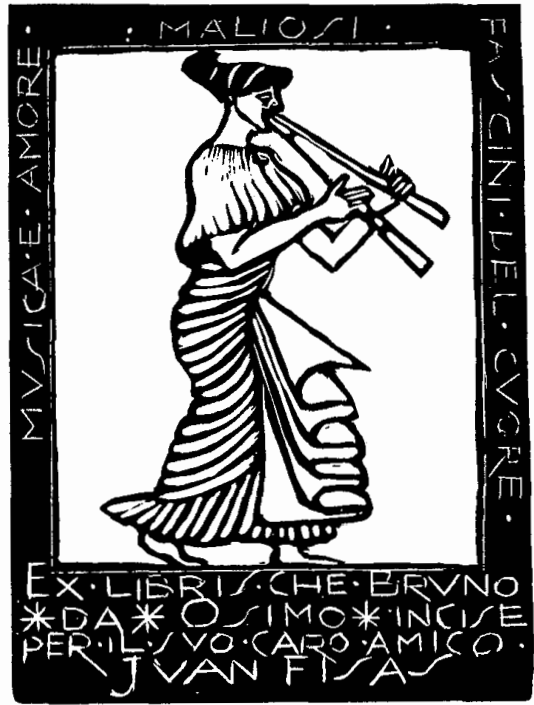

nivel federal, es en el poder legislativo -específicamente en la Cámara de Diputados-, donde la participación femenina se ha dado en mayor número $y$ ha ido en aumento; no obstante:

[...] si bien a partir de $1953,350 \mathrm{mu}$ jeres han llegado a ocupar curules en el Congreso de la Unión, su presencia no ha significado, cuando menos en forma destacada, cambios significativos en la legislación en pro de la igualdad de género, quizá porque durante décadas las curules otorgadas a las mujeres fueron resultado de una cuota no reglamentada que estableció el partido en el poder para el sector femenino. Décadas en las que el PRI mantuvo el monopolio absoluto de los puestos de elección popular. ${ }^{16}$

${ }^{16}$ Lovera y Casas, "Elecciones", 1992, p. 7. 
En el caso del poder legislativo para este estado, la presencia de mujeres en dicho órgano de gobierno puede ubicarse en los comicios electorales para integrar el Congreso Constituyente, que entró en funciones en el periodo 1974 a 1977. En esa ocasión fueron elegidos siete diputados al Congreso, y entre ellos una mujer; la primera senadora suplente fue Prisca Melgar de Tuchman (1976-1982); posteriormente, tres mujeres más ocuparian curules, también en la modalidad de suplencias, todas ellas militantes prístas.

Como ya se indica en la cita anterior, las curules ocupadas por mujeres están supeditadas a la llamada "cuota" que, por "tradición" o interés, les asigna el partido oficial en las contiendas electorales. Cabe señalar que esta "cuota" no es privativa del PRI, dado que, en la mayoría de los partidos que han participado en comicios electorales para integrar las legislaturas de este estado, las mujeres conforman cifras poco significativas. Lo que más impresiona es que cuando ellas deciden participar en partidos políticos y dejan de permanecer en el ámbito de "lo privado", no resultan cifras más altas de participación en las candidaturas a cargos de elección popular. ${ }^{17}$

De las siete legislaturas que ha tenido este estado ( $\mathrm{y}$ en las cuales el número de diputados se ha ido modificando merced a los cambios en la normatividad de los procesos electorales y al número de partidos que han participado en los comicios), del número total de diputados propietarios, el $8.4 \%$ han sido mujeres. Las cifras

\footnotetext{
${ }^{17}$ Véase González, "Mujeres", 1994, pp. 8-9.
}

para el caso de las suplencias presentan un porcentaje mayor con $26.5 \%$ de mujeres respecto a un total de $73.4 \%$ de hombres (cuadro 4); diferencia porcentual entre propictarias y suplentes que se observa con idéntica tendencia a nivel federal. A excepción de la Legislatura actual, donde existen dos diputadas propietarias por el Partido Acción Nacional, en las seis legislaturas precedentes se mantuvo constante una diputada propietaria por el Partido Revolucionario Institucional. El hecho de que dos mujeres del paN ocuparan ahora la titularidad en el Congreso local, se explica por las importantes victorias que este partido obtuvo en los comicios para diputados y en las presidencias municipales. Este dato, aunque aislado, no deja de ser significativo en tanto que, por vez primera, se vio incrementado el número de mujeres en las curules. Los datos anteriores tienden a confirmar la hipótesis de que, a la militancia previa en los partidos políticos, sigue el "rito de iniciación o de transición": la suplencia. Las opiniones vertidas en los testimonios de las funcionarias entrevistadas respecto a esta situación es muy elocuente:

Los puestos en donde puede haber suplentes son, por ejemplo, puestos que el partido sabe muy bien que nunca van a llegar a ser suplencias efectivas [...] para ellos es un dolor de cabeza que tenga que dejarlo el propietario propuesto y dejar a la suplente [...] en puestos clave rara vez se manejan suplentes mujeres, cuando van a dejar el puesto los propietarios. Si se examinan las características de estas mujeres, éstas son las que se foguearon en la po- 


\section{SECUENCIA}

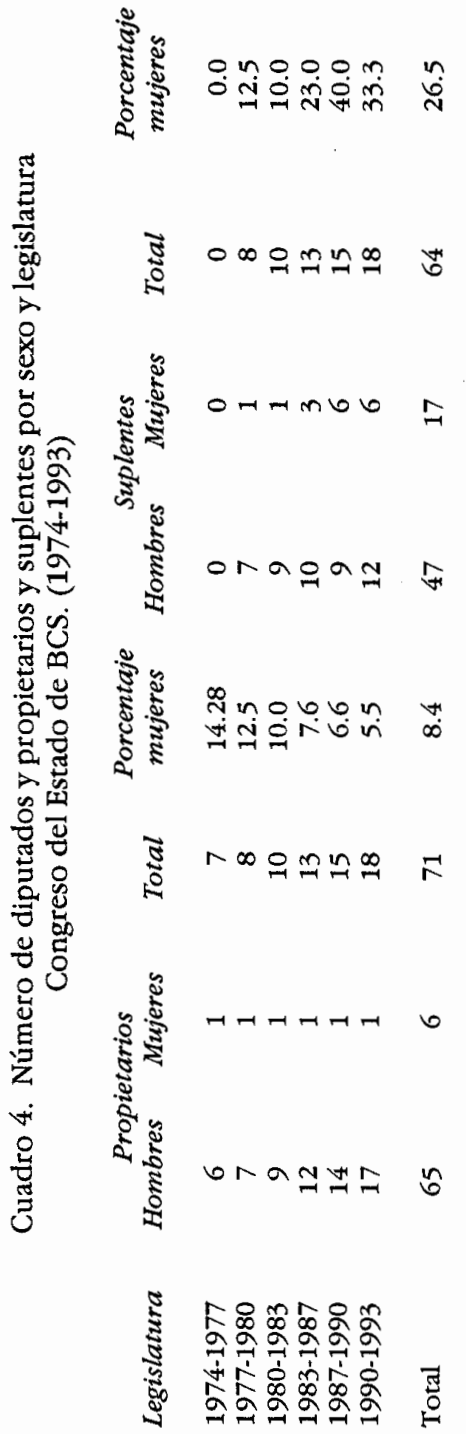




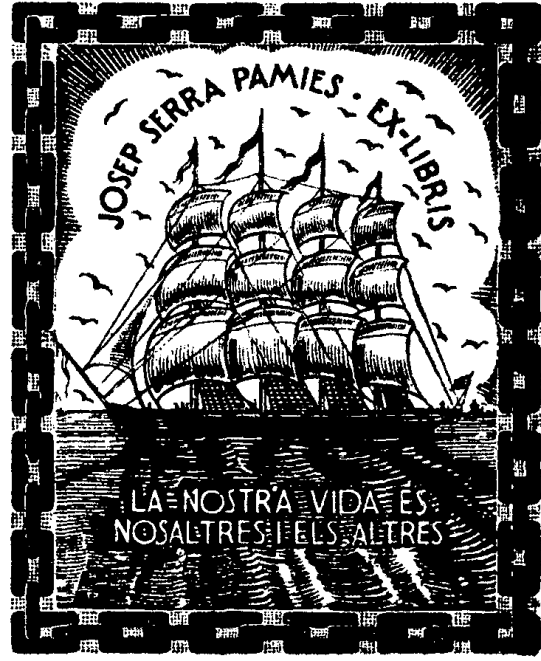

lítica de los hombres, su discurso político es de hombres, obedecen a los intereses del partido en ese sentido [...] se requieren mujeres que garanticen la continuidad de la ideología del partido, respeto a la línea política. ${ }^{10}$

La militancia de las mujeres en el PRI está íntimamente vinculada a los sectores femeniles (CIM, FNOC) y, en consecuencia, no se encuentran excluidas de participar. Es interesante constatar que, las funcionarias que declaran mantener una relación contingente, casi "accidental", con el partido oficial, opinan que, si bien la militancia partidista es importante, los sectores femeniles deben desaparecer. Varios factores contribuyen a esta

${ }^{10}$ Testimonio de Cinthia Castro Iglesias. opinión generalizada: su perfil socioprofesional, su trayectoria dentro del sector público (su relativo "éxito"), y el hecho de haberse incorporado al servicio público sin militar previamente en ningún partido político.

Las "políticas técnicas" hacen política desde una posición de privilegio respecto a sus "correligionarias" de partido, dado que no han sufrido las vicisitudes de las mujeres de base para llegar a ocupar un cargo. Pasar los "filtros", competir entre mujeres, cuidar una imagen pública y demostrar, a pesar de todo, lealtad al partido, son problemas que muchas funcionarias "prefieren evitar".

Se afirma que la presencia de las mujeres en puestos de poder político, sea dentro de la administración pública, las cámaras o el partido, es importante en virtud de que es el lugar don. de se elabora, se ejecuta y se da seguimiento a la normatividad jurídica que atañe a los grandes problemas de nuestro país y, en consecuencia, tiende a disminuir la desigualdad entre los sexos. Sin embargo, dicha justificación no da cuenta de la intencionalidad de las prácticas políticas ejercidas por las propias mujeres, dado que, en su mayoría, no se identifican con reivindicaciones "propias de su sexo" o feministas, salvo algunas excepciones. ${ }^{19}$ Difícilmente podemos afirmar que las mujeres, por el hecho de serlo biológicamente, imprimen al desempeño de sus cargos y al ejercicio del pocler una tónica distinta a la que, tradicional-

\footnotetext{
${ }^{19}$ Un ejemplo de ello lo constituye la reciente creación de la Subprocuraduría de Atención de la Mujer y el Menor.
} 
mente, conocemos como práctica de los hombres, sin embargo, la subjetividad y la experiencia femenina rescatada en los testimonios apuntan en dos direcciones opuestas. Por un lado tenemos quienes opinan lo siguiente:

[...] yo siento que no somos muy políticas las mujeres que hemos estado en la administración pública, sino, más que todo, profesionales $[\ldots]$ ser una profesionista dentro de la política es muy difícil, si tú quieres seguir una ética en todo tu quehacer; en determinado momento quieren que seas como ellos y que tomes decisiones políticas y eso sí es lo que te crea conflictos [...] con mujeres, yo no tuve problemas precisamente porque no eran políticas [...] de ahí que se contraponen los intereses de los políticos con las mujeres que estamos en la administración pública; nosotros, para sostenernos en una actividad, difícilmente vamos a realizar lo mismo que ellos $[\ldots]$ por eso justifico las secciones femeniles. ${ }^{20}$

\section{Otras, por el contrario afirman:}

Yo no justifico las secciones femeniles dentro del partido (PRI); no las justifico porque volvemos a lo mismo, estamos compitiendo entre nosotras mismas, creo que la competencia no debe darse entre mujeres, se debe dar entre individuos sin importar sexos $[\ldots]$ y se debe dar simple y sencillamente porque eres competente, por capacidad [...] es una medida de presión para llegar a ciertas posiciones, pero una vez

20 Testimonio oral obtenido de la Lic. Concepción Acosta Mendía, cCSYH-UABCS, Archivo de la Palabra, Serie Mujeres, La Paz, 1994. Ocupó el cargo de directora del Instituto de Capacitación de los Trabajadores al servicio del Estado por dos administraciones consecutivas.

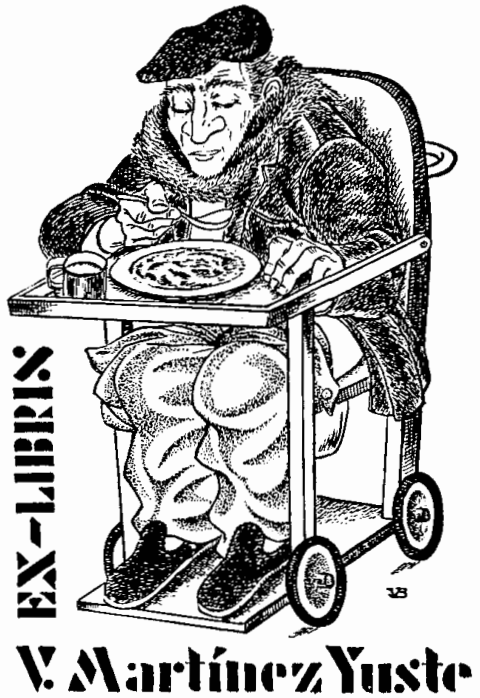

que las logras, ya no se justifica continuar con las secciones. ${ }^{21}$

De lo anterior se desprende que, en la práctica, las mujeres funcionarias no constituyen un bloque homogéneo; algunas veces la solidaridad entre mujeres se expresa en la oportunidad que algunas de ellas brindan a otras para ocupar cargos de menor jerarquía; otras prefieren el trabajo con varones dado que las relaciones con otras mujeres son calificadas de "muy conflictivas".

Se percibe un ambiente de competitividad, acentuado quizá por los perfiles socioprofesionales y la pertenencia o simpatía hacia grupos que se disputan el poder, así como también a

${ }^{21}$ Testimonio oral de la C.P. Griselda Uribe Figueroa. 
causa de las funcionarias más jóvenes recientemente incorporadas al sector público (que constituyen un grupo generacional profesionalmente hablando) que, dada la tendencia histórica en cuanto a oportunidades de desarrollo, son una "amenaza latente" en el cuanto a desplazamiento en los cargos.

\section{REFLEXION FINAL.}

Las condiciones históricas en lo concerniente a la evolución político-administrativa de Baja California Sur (como son las fechas relativamente recientes en que esta entidad se convirtió en estado y la presencia activa de los partidos que no fueron el espacio privilegiado para la participación política ciudadana) explicarían, por lo menos parcialmente, la tardía y precaria presencia de las mujeres en la elite política. Pero el cambio en el estatuto político de territorio a estado y la consolidación de una plataforma estable en los partidos políticos no han sido, según los datos obtenidos, las condiciones necesarias y suficientes que han favorecido la incorporación femenina al sector público.

Las pautas de ingreso, permanencia y acceso a oportunidades de desarrollo de las mujeres se explica, más bien, por los cambios sustanciales observados en relación con variables tales como sus perfiles socioprofesionales y la ausencia de una militancia previa y continua en el partido oficial. En relación con el número de mujeres y el tipo de cargos que, preferentemente, éstas han ocupado en los órganos de gobierno local, podemos afirmar que las cifras son poco significativas; las direcciones y jefaturas de departamento en el ejecutivo, el de jueces en el judicial, y las diputaciones con carácter de suplencias en el legislativo, es donde se concentra cl mayor porcentaje de funcionarias públicas. Se puede afirmar entonces que, tanto a nivel federal como estatal, no existen diferencias sustanciales en números relativos respecto a su presencia. Los testimonios ofrecen algunas "pistas" para suponer que las funcionarias han vivido una particular condición de sujeción a las "reglas del juego" impuestas por las prácticas ancestrales de ejercicio del poder masculino, sin embargo, éste se ve contrarrestado por sus características de eficiencia en las relaciones interpersonales.

No encontramos suficientes elementos para afirmar que las funcionarias políticas hayan representado una alternativa distinta en el ejercicio del poder respecto de sus pares varones, o si se prefiere un antipoder opuesto al de ellos; si bien sus itinerarios varían sustancialmente del que por tradición se espera de las "mujeres", tampoco difieren mucho de los que los hombres realizan en tanto que micmbros de la elite política. Quizá cl rasgo más significativo a destacar sca su condición de instrumento, habida cuenta de que continúan situadas siempre por debajo de quien toma las decisiones políticas importantes; a pesar de ello y con mayor o menor supeditación al poder masculino ejercido en el ámbito político, las funcionarias políticas no se sienten víctimas.

Lo anterior es particularmente importante no sólo por razones de or- 
den teórico, por ejemplo la discusión en torno a la crítica del denominado "feminismo de la igualdad $v s$. feminismo de la diferencia", 22 sino también de orden práctico, por ejemplo, la denominada "discriminación positiva" (demanda del establecimiento de una cuota fija de mujeres en los comicios electorales).

La ausencia de estudios que no privilegien la cuantificación, aunque necesarios, es notoria, y debieran atender, por lo menos, tres áreas primordiales: 1) La caracterización de las elites políticas en las distintas entidades federativas. 2) Los procesos de inserción, permanencia y movilidad de hombres y mujeres en las elites. 3) El análisis de las diferencias (si es que las hay) en los estilos de liderazgo y pautas éticas en el ejercicio del poder entre hombres y mujeres.

Por ello es importante introducir en los estudios sobre mujeres y política los conceptos de género y poder, y es necesario hacerlo desde una posición teórico/metodológica que permita acceder a la subjetividad de los actores (y actrices) políticos, es decir, de irrumpir en el campo denominado construcción de sentido, para desentrañar el contenido simbólico presente en los estereotipos, estrategias e identidades asignados, sociocultural e históricamente, a los seres sexuados.

Lo anterior supone asumir las siguientes premisas: $a$ ) que toda posición de sujeto (hombres y mujeres) es múltiple y relativa, es decir, que participa del carácter abierto de todo

\footnotetext{
${ }^{22}$ Véase Scott, "Igualdad", 1992; y Gutiérrez, "Igualdad", 1997.
}

discurso y, por tanto, no logra fijar su identidad de una vez y para siempre (en este sentido podemos accptar que las trayectorias de vida nos ofrecen "signos de identidad" interiorizados que tienden a reforzar o resignificar el género asignado, según el estatuto biológico, a una persona; $b$ ) que la posibilidad de resignificación de los referentes o significantes asignados a la identidad de género originalmente impuesta, puede modificarse a lo largo de toda la vida y, en ese sentido, "hacer suyos" otros rasgos de identidad; c) si lo anterior es factible, entonces la crítica feminista al esencialismo filosófico ${ }^{23}$ y político de la "naturaleza femenina" es válida, toda vez que constituye un rechazo a la noción preconstruida sobre la "opresión de las mujeres" y su consecuente victimización; $d$ ) que esta crítica no es ciega a la condición de subordinación de las mujeres al poder simbólico masculino, condición de opresión/exclusión que el género femenino comparte con otros grupos sociales, desvalorizados culturalmente por razones de preferencia sexual, etnia o edad.

Lo anterior permite pensar en la posibilidad de cambios de identidad que no sólo pueden ser reivindicadores del respeto a la diferencia, sino de afirmación de la diferencia si sc exige trato igual en un régimen de libertades civiles. ${ }^{24}$ Finalmente, hay que apuntar que evaluar el equilibrio en-

${ }^{23}$ Véase Valcárcel, Sexo, 1991.

${ }^{24}$ Sobre la polémica actual respecto a las denominadas "políticas de la redistribución vs. políticas de reconocimiento", consúltese a Fraser, "Redistribución", 1996. 
tre el estereotipo sumisión/subversión en lo que concierne a los valores asignados por las mujeres en su práctica política sólo será posible deslindando, por un lado, el discurso de éstas sobre su propio comportamiento $y$, por otro, el de la posición relativa que, en tanto que sujetos políticos, se imprime a su identidad de género.

\section{BIBLIOGRAFIA}

-Burín, Mabel y Emilce Bleichmar (comp.), Género, psicoanálisis y subjetividad, Paidós, Buenos Aires, 1996 (Psicología Profunda).

-De Silva, Luz de Lourdes, "Las mujeres en la elite política de México: 19541984 " en Orlandina de Oliveira (comp.), Trabajo, poder y sexualidad, PIEM/EI Colegio de México, México, 1989.

- Farías Mackey, María Emilia, "La participación de la mujer en la política" en Juan Manuel Ramírez Sáiz, et al., México, setenta y cinco años de revolución, $\mathrm{FCE} /$ INEHRM, México, 1988, vol. II.

- Fraser, Nancy, "Repensar el ámbito público: una contribución a la crítica de la democracia realmente existente", Debate Feminista, año 4, vol. 7, marzo, 1993, México.

-González, Rosa María, "Mujeres en la lucha electoral", La Jornada, 4 de julio, 1994, México, Suplemento Doble Jornada.

-Gutiérrez, Griselda,"Igualdad y diferencia: un universalismo acotado", México, 1997 (mimeografiado).

-Lamas, Martha, "La antropología feminista y la categoría de género", Nueva Antropología, vol. vII, núm. 30, noviembre, 1988, México.

-Lovera, Sara y Yoloxóchitl Casas, Las elecciones de las mujeres: propuestas legislativas, Casa de las Américas, México, 1992.
-Martínez F., Alicia Inés (comp.), Mujer, gobierno y sociedad civil, FLACSO, México, 1993.

"De poder, podemos: diferencias genéricas en la clinámica sociopolítica", El Cotidiano, núm. 53, marzoabril, 1993, México.

-Moss Kanter, Rosabeth, "Cambio de las restricciones organizacionales hacia la promoción de oportunidades y trato equitativo a la mujer en los sistemas del servicio público" en Irma Cue Sarquis (comp.), Formulación de políticas para incrementar la participación de la mujer en la administración pública, Porrúa/ ONU, México, 1990.

-Peña Molina, Blanca Olivia, "Identidad y estrategia de género en la elite política de Baja California Sur: ¿Son las mujeres aliaclas naturales?", México, 1997 (mimeografiado).

-Preciado Llamas, Juan, "El cliscurso regionalista en Baja California Sur: 19201981" en Alfonso Guillén Vicente (comp.), Baja California Sur: los procesos politicos y el cambio institucional, SEP/UABCs/ CIH, La Paz, 1987.

, "Producción, trabajo y gobierno en Sudcalifornia entre el maximato y el cardenismo: 1932-1937" en María Eugenia Altable, et al., Estudios de bistoria sudcaliforniana, SIHR/UABCS, La Paz, 1993.

-Randall, Vicky, Women and politics: an international perspective, Mcmillan Press, Londres, 1987.

-Rossanda, Rossana, Las otras, Ed. Gedisa, Barcelona, México, 1982.

-Scott, Joan W., "Igualdad $v s$. diferencia: los usos de la teoría posestructuralista" en Debate Feminista, vol. 5, año 3, marzo, 1992, México.

, "El género: una categoría útil para el análisis histórico" en $E l$ géne. ro: la constitución cultural de la diferencia sexual, pubg/Unam, México, 1996.

-Valcárcel, Amelia, Sexo y filosofía. Sobre mujer y poder, Ed. Anthropos, Barcelona, 1991. 